University of Nebraska - Lincoln

DigitalCommons@University of Nebraska - Lincoln

USDA National Wildlife Research Center - Staff Publications
U.S. Department of Agriculture: Animal and Plant Health Inspection Service

2013

\title{
Patterns of Human-Coyote Conflicts in the Denver Metropolitan
} Area

Sharon A. Poessel

Utah State University, sharpoes@gmail.com

Stewart W. Breck

USDA/APHIS/WS National Wildlife Research Center, stewart.w.breck@aphis.usda.gov

Tara L. Teel

Colorado State University - Fort Collins, tteel@lamar.colostate.edu

Stephanie A. Shwiff

USDA/APHIS/WS National Wildlife Research Center, stephanie.a.shwiff@aphis.usda.gov

Kevin R. Crooks

Colorado State University - Fort Collins, kevin.crooks@colostate.edu

See next page for additional authors

Follow this and additional works at: https://digitalcommons.unl.edu/icwdm_usdanwrc

Poessel, Sharon A.; Breck, Stewart W.; Teel, Tara L.; Shwiff, Stephanie A.; Crooks, Kevin R.; and Angeloni, Lisa, "Patterns of Human-Coyote Conflicts in the Denver Metropolitan Area" (2013). USDA National Wildlife Research Center - Staff Publications. 1183.

https://digitalcommons.unl.edu/icwdm_usdanwrc/1183

This Article is brought to you for free and open access by the U.S. Department of Agriculture: Animal and Plant Health Inspection Service at DigitalCommons@University of Nebraska - Lincoln. It has been accepted for inclusion in USDA National Wildlife Research Center - Staff Publications by an authorized administrator of DigitalCommons@University of Nebraska - Lincoln. 


\section{Authors}

Sharon A. Poessel, Stewart W. Breck, Tara L. Teel, Stephanie A. Shwiff, Kevin R. Crooks, and Lisa Angeloni 


\title{
Patterns of Human-Coyote Conflicts in the Denver Metropolitan Area
}

\author{
SHARON A. POESSEL, ${ }^{1}$ Department of Fish, Wildlife, and Conservation Biology, Colorado State University, Fort Collins, CO 80523, USA \\ STEWART W. BRECK, ${ }^{2}$ United States Department of Agriculture-Wildlife Services-National Wildlife Research Center, Fort Collins, CO 80521, \\ USA \\ TARA L. TEEL, Department of Human Dimensions of Natural Resources, Colorado State University, Fort Collins, CO 80523, USA \\ STEPHANIE SHWIFF, United States Department of Agriculture-Wildlife Services-National Wildife Research Center, Fort Collins, CO 80521, USA \\ KEVIN R. CROOKS, Department of Fish, Wildlife, and Conservation Biology, Colorado State University, Fort Collins, CO 80523, USA \\ LISA ANGELONI, Department of Biology, Colorado State University, Fort Collins, CO 80523, USA
}

\begin{abstract}
In many cities throughout North America, human-coyote conflicts are an emerging problem. Little research has described temporal and spatial patterns of human-coyote conflicts, although such information can be an important step in developing and optimizing management efforts. We used reports from 22 entities within the Denver Metropolitan Area (DMA) in Colorado that provided information on coyote observations (signs, sightings, and encounters) and conflicts (incidents, pet-attacks, and humanattacks). Our objectives were to 1 ) define, quantify, and map categories of coyote observations and conflicts, and 2) investigate temporal and spatial patterns of conflicts, particularly related to land cover types and housing density classes. We compiled 4,006 coyote reports, including 78 signs (1.9\%), 3,023 sightings (75.5\%), 395 encounters (9.9\%), 26 incidents (0.6\%), 471 pet-attacks (11.8\%), and 13 human-attacks (0.3\%). We found a strong seasonal pattern with reports of both observations and conflicts highest during DecemberMarch and lowest during July-September. Numbers of coyote conflicts were disproportionately greater in open space and development land cover types (in contrast to natural and agricultural land cover) and in suburban housing areas (in contrast to urban, exurban, and rural areas). Hotspots of coyote conflicts were apparent in the southern region of the DMA, possibly because coyotes had better access to development, and hence interaction with residents, via natural areas bordering urban areas; reporting bias may have also influenced this outcome. Our results will help target management efforts, particularly those focused on people (e.g., education), but also highlight the critical need for improved methods of collecting conflict information via a standardized reporting mechanism to help reduce bias. (c) 2012 The Wildlife Society.
\end{abstract}

KEY WORDS Canis latrans, conflict, coyote, Denver, sighting, spatial, urban.

The proportion of humans residing in urban areas is continually increasing, affecting biodiversity and motivating increased focus on wildlife conservation in urban environments (McKinney 2002, Marzluff et al. 2008, Mcdonald et al. 2008, Pickett et al. 2008). Some wildlife species are able to persist, and even thrive, in urban systems, particularly generalist species that can utilize a variety of natural and anthropogenic resources available in urban landscapes (Crooks 2002, Gehring and Swihart 2003, Fuller et al. 2010). At times, these species can cause conflict that is often pronounced in urban environments (e.g., risks to pets and humans; Mansfield and Torres 1994, Knowlton et al. 1999) and that compels wildlife managers to consider a variety of emerging issues associated with urban wildlife (Gehrt 2010).

Received: 14 October 2011; Accepted: 22 June 2012

Published: 23 August 2012

${ }^{1}$ Present address: Department of Wildland Resources, Utah State University, 5230 Old Main Hill, Logan, UT 84322-5230, USA.

${ }^{2}$ E-mail: stewart.w.breck@aphis.usda.gov
Many carnivore species have demonstrated an ability to persist in urban environments (Beier 1995, Riley et al. 1998, Crooks 2002, Baruch-Mordo et al. 2008, Gehrt et al. 2010). Coyotes (Canis latrans) are often found in urban areas (Grinder and Krausman 1998, Gehrt et al. 2009), in part because they are highly adaptable, opportunistic carnivores and habitat generalists (Bekoff and Gese 2003, Morey et al. 2007, Levy 2012), but also because urban sprawl has encroached into natural areas, creating a wildland-urban interface containing both humans and coyotes. In general, coyotes can live in close proximity to humans with little threat to people (Gehrt et al. 2009), but in some situations, conflicts, especially with pets, are emerging as an important consideration for urban managers (Crooks and Soulé 1999, Gehrt et al. 2009, Lukasik and Alexander 2011).

Relatively little research has been conducted on coyotes in highly urban areas (Gehrt and Riley 2010), and most of the work that has been done has focused on coyote ecology (Quinn 1997; Grinder and Krausman 2001a, b; Tigas et al. 2002; Riley et al. 2003; Morey et al. 2007; Gehrt 
et al. 2009) and not on spatial and temporal patterns of human-coyote conflicts (but see Lukasik and Alexander 2011). Reports of coyote sightings and conflicts have gained greater attention in recent years in the Denver Metropolitan Area (DMA), a rapidly urbanizing region in Colorado that has doubled in population size since 1960 (Magle et al. 2010). For example, reports of coyotes and conflicts generated 27 articles in the regional newspaper, the Denver Post, in 2009 alone (Denver Post 2010).

Human-wildlife conflicts can affect human health and safety, imposing costs on individuals and public wildlife managers, and can have negative consequences for wildlife and conservation. As a result, minimizing these types of conflicts has become a priority for many urban wildlife managers, city and county officials, and community residents (Hudenko et al. 2010). For most species, including coyotes, limited knowledge exists about patterns of conflict. Increasing evidence suggests that conflicts can be clustered in space and time (Thirgood et al. 2005, Baruch-Mordo et al. 2008), and understanding these patterns can assist in targeting management activities to mitigate human-wildlife conflicts. Synthesis of available descriptive conflict data forms the foundation for conflict minimization and successful optimization of management actions. In recognition of this, our objectives were to 1) define, quantify, and map categories of coyote observations and conflicts in the DMA, and 2) investigate temporal and spatial patterns of conflicts, particularly related to land cover types and housing density classes.

\section{STUDY AREA}

The DMA includes sections of 6 counties (Adams, Arapahoe, Boulder, Denver, Douglas, and Jefferson), all of Broomfield County, and over 45 municipalities in north-central Colorado (Fig. 1). The estimated human population of the 7 counties as of 1 January 2007 was approximately 2.8 million (Denver Regional Council of Governments 2010). The DMA is located in the Front Range of Colorado and is situated between grasslands and agricultural lands to the east and the foothills of the Rocky Mountains to the west. The elevation of the city of Denver is approximately $1,610 \mathrm{~m}$; the climate is semi-arid with temperatures ranging from $-34^{\circ} \mathrm{C}$ to $38^{\circ} \mathrm{C}$ and annual precipitation of less than $38 \mathrm{~cm}$ (Bruce and McMahon 1996). Historically, lands within the DMA consisted of primarily grassland habitat, but now incorporate a variety of land cover types, including agriculture, grasslands, woodlands, and urban development.

\section{METHODS}

We obtained data on coyote reports for the period January 2003-June 2010 from 22 entities, including 16 municipalities, 5 county governments, and Colorado Parks and Wildlife. The entities collected data over 1-8 years and used a variety of methods, including calls from citizens, online reports from citizens, and employee observations; of the 2,021 reports $(50.4 \%)$ where the origin could be identified, the vast majority (93.8\%) were from citizens. Data recorded included the date, location, and type of report.
We divided coyote reports into 2 types, observations and conflicts. Each of these types was further divided into 3 categories. Observations included signs, sightings, and encounters, and conflicts included incidents, pet-attacks, and human-attacks (see Table 1 for definitions). The 6 categories represented an increasing degree of interaction between humans and coyotes. Some entities did not use all categories, but when available, we used the detailed description of each coyote report to help classify reports and to further describe the nature of particular types of conflicts. Specifically, for human-attacks we used additional comments to address whether pets were involved when the coyote attacked a human (e.g., the human was walking a dog at the time of attack); such instances were classified as human-attacks rather than pet-attacks. For pet-attacks, we used additional comments to address the context of the attack, including where it occurred (i.e., enclosed backyard, near a house, in open space with a dog on-leash, in open space with a dog off-leash) and the type of pet (e.g., cat or $\mathrm{dog}$ ). We input the locations of each report into ArcMap v. 10 (Environmental Systems Research Institute, Inc., Redlands, CA).

We documented 3 types of temporal patterns in the data: yearly, monthly, and seasonal. First, we calculated total percentages of each of the 6 report categories (Table 1) and summarized these across years to investigate yearly trends. To investigate monthly trends, we determined the number of coyote reports by month within each category, summed across all years and entities, and then calculated monthly percentages by dividing the reports for each month by the total number of reports. Finally, we categorized coyote reports into biological seasons (Morey et al. 2007): breeding (1 Jan-30 Apr), pup-rearing (1 May-31 Aug), and dispersal (1 Sep-31 Dec). We tested for differences in frequency of reports among seasons using a chi-squared contingency test.

To evaluate spatial trends, we focused on coyote conflicts only. We first determined densities of conflicts to identify hotspots in the DMA. We used the Kernel Density tool in ArcMap to create density contours around the conflict locations. This tool calculates a magnitude per unit area from point data using a kernel function to fit a smoothly tapered surface to each point. We divided the contours into 4 categories to represent no, low, medium, and high densities using the natural breaks classification within the tool, where classes are based on natural groupings inherent in the data, and break points are chosen that best group similar values and maximize the differences between classes. Because the Kernel Density tool assigns a value to every pixel in a rectangular grid area, and our goal was to identify substantial hotspots of conflict densities in the DMA, we removed the lowest category representing the smallest densities (i.e., 00.3 conflicts $/ \mathrm{km}^{2}$ ), and mapped the remaining 3 categories representing low (0.3-1.4), medium (1.4-3.6), and high (3.6-8.6) conflicts $/ \mathrm{km}^{2}$. We then conducted a multidistance spatial cluster analysis using Ripley's $K$-function (Haase 1995) with distance bands between $1,500 \mathrm{~m}$ and $15,000 \mathrm{~m}$ to determine whether coyote conflicts were significantly clustered throughout the study area. The study area 


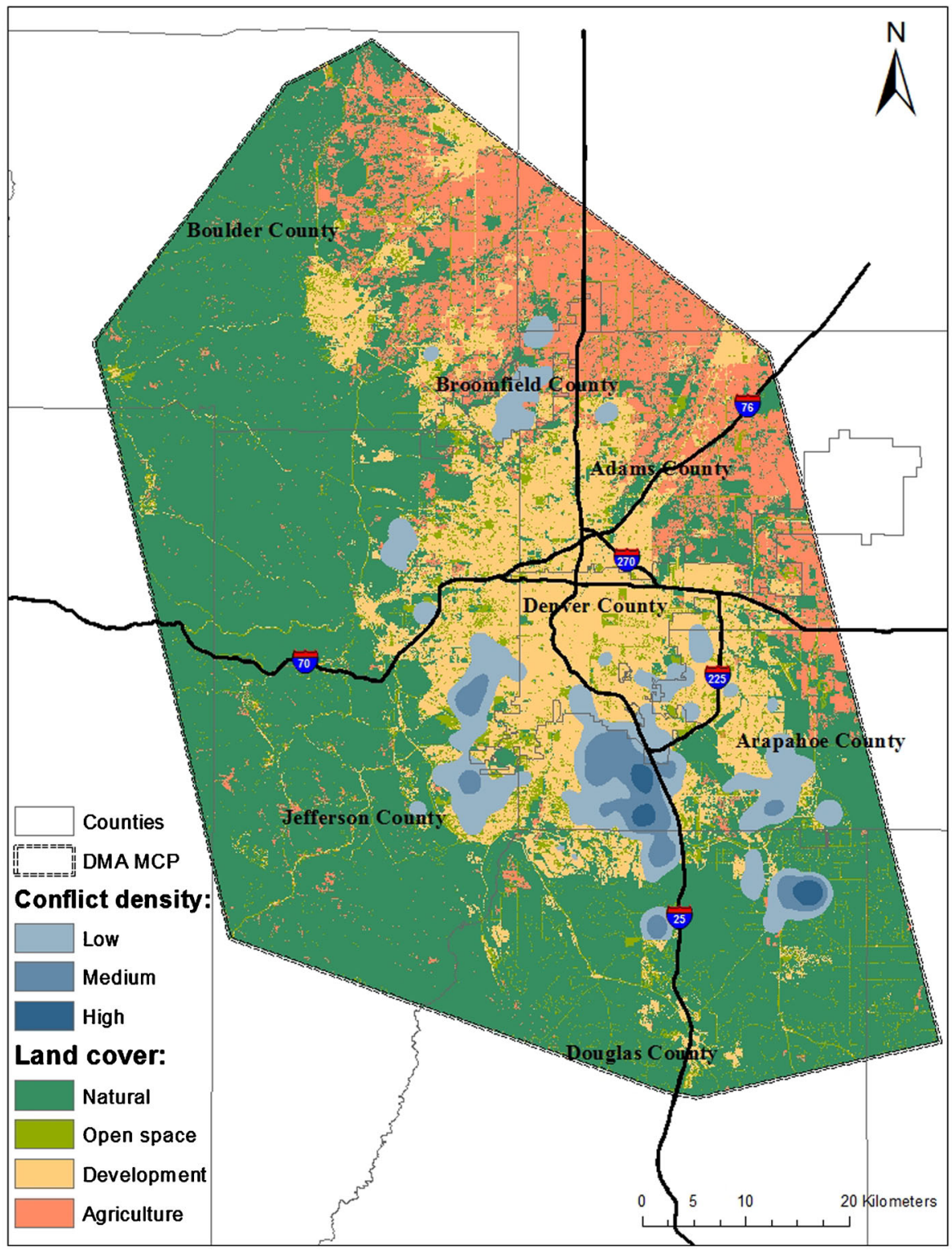

Figure 1. Map of the Denver Metropolitan Area (DMA) showing densities of coyote conflicts (defined as incidents, pet-attacks, and human-attacks) reported for 2003-2010 across the 4 primary land cover types. The minimum convex polygon (MCP) containing all coyote reports within the DMA is outlined. We calculated density with a kernel density function categorized into low (0.3-1.4), medium (1.4-3.6), and high (3.6-8.6) conflicts/km².

was determined by creating a minimum convex polygon (MCP) around all coyote reports (Fig. 1).

Next, we tested whether conflicts were associated with particular land cover types or housing density classes. We classified land cover types in the DMA into 10 categories (Table 2) derived from the Landscape Fire and Resource Management Planning Tools Project (LANDFIRE), a national geospatial dataset with 30-m resolution using imagery

Table 1. Categories of coyote reports, their associated definitions, and the percent of total reports within each category in the Denver Metropolitan Area, 20032010 ( $n=4,006$ total coyote reports).

\begin{tabular}{|c|c|c|}
\hline Coyote report & Definition & $\%$ of total reports \\
\hline \multicolumn{3}{|l|}{ Observations } \\
\hline Sign & The act of noticing or taking note of tracks, scat, or vocalizations & 1.9 \\
\hline Sighting & A visual observation of a coyote(s) & 75.5 \\
\hline Encounter & An unexpected direct meeting between a human and a coyote that is without incident & 9.9 \\
\hline \multicolumn{3}{|c|}{ H } \\
\hline Incident & $\begin{array}{l}\text { A conflict between a human and a coyote where a coyote exhibited behavior creating an unsafe situation for } \\
\text { the human; includes baring teeth, growling, snarling, stalking a human, or crouching as if to attack a human }\end{array}$ & 0.6 \\
\hline Pet-attack & Domestic pet is attacked by a coyote (either injured or killed) & 11.8 \\
\hline Human-attack & $\begin{array}{l}\text { A conflict that involves physical contact between a coyote and a human; a human is injured or killed by a } \\
\text { coyote }\end{array}$ & 0.3 \\
\hline
\end{tabular}


Table 2. Land cover types evaluated for coyote observations and conflicts in the Denver Metropolitan Area, 2003-2010. For analyses, forest, shrub, grassland, sparse, barren, open water, and wetlands land cover types are combined into a natural category.

\begin{tabular}{ll}
\hline Land cover type & \multicolumn{1}{c}{ Description } \\
\hline Forest (natural) & All forested areas, including deciduous, evergreen, and mixed forest, and including open, closed, and sparse tree canopy \\
Shrub (natural) & Areas dominated by shrubs \\
Grassland (natural) & Areas dominated by graminoid or herbaceous vegetation \\
Sparse (natural) & Sparsely vegetated areas \\
Barren (natural) & Non-vegetated areas \\
Open water (natural) & All areas of open water, including areas of ice in winter \\
Wetlands (natural) & Areas with forest, shrub, or herbaceous vegetation where the soil or substrate is periodically saturated with or covered with water \\
Agriculture & Pasture/hay fields, cultivated crops, and irrigated agricultural systems \\
Open space & Includes parks, golf courses, and vegetation planted in developed settings for recreation or aesthetic purposes \\
Development & All commercial and residential human-developed areas \\
\hline
\end{tabular}

from 1999 to 2003 developed to support wildland fire management and planning (Rollins and Frame 2006). We further condensed these 10 categories into 4 broad habitat types: 1 ) natural, consisting of the 5 naturally-occurring vegetative land cover types (forest, shrub, grassland, sparse, and barren) and the 2 water land cover types (open water and wetlands); 2) development; 3) open space; and 4) agriculture (see Table 2 for descriptions). We then calculated proportions of coyote conflicts within each habitat type, along with proportions of each land cover type available within the MCP study area.

We obtained data on human density from the Spatially Explicit Regional Growth Model (SERGoM v1; Theobald 2005) with 100-m resolution, which depicts housing density based on 2000 United States Census Bureau data. We defined urban housing densities as less than 0.1 ha per unit, suburban densities as $0.1-0.68$ ha per unit, exurban densities as $0.68-16.18$ ha per unit, and rural densities as greater than 16.18 ha per unit (Theobald 2005); we included industrial and commercial development in the urban category. We then calculated proportions of coyote conflicts within each type of housing density, along with proportions of each housing density class available within the MCP study area. We were unable to determine a location for $11(2 \%)$ of the coyote conflicts, so we did not include these conflicts in spatial analyses. We also did not include 62 coyote conflicts $(12 \%)$ in the housing density analysis because they were located on undeveloped land (i.e., undeveloped public and private land and parks) rather than within any of the 4 housing density classes. Because our land cover analysis examined natural versus developed areas, we focused our housing density analysis on evaluating the intensity of development.

We used a chi-squared analysis to test for significant differences between the expected (based on availability) and observed coyote conflicts among land cover types and housing density classes. We calculated expected coyote conflicts in each type or class as the total number of conflicts multiplied by the relative area of the DMA within each type or class. If the null hypothesis of random selection in proportion to availability was rejected, we then determined which land cover types and housing density classes were selected more or less often than expected by constructing simultaneous Bonferroni confidence intervals $\left(\alpha=0.05, k=4, Z_{\alpha / 2 k}=Z_{0.00625}=2.50\right)$ around the proportion of land cover and housing density use and comparing these with the available proportion (Neu et al. 1974, Byers and Steinhorst 1984). We conducted statistical analyses in SAS (SAS Institute Inc. 2008).

We emphasize that the data we received on coyote reports reflect patterns not only in coyote activity in the DMA, but also in sampling effort by the entities and reporting rates by residents. Thus, we consider several possible biases in the data collection and reporting. First, the various entities used different methods to collect their data. Some coyote reports were generated by citizens, whereas others were based on reports from agency employees who may have more expertise in identifying coyotes. Also, some of the entities (41\%) did not provide detailed descriptions of each coyote report; hence, the category assigned to these reports by the entity could not be verified, so we used the provided category. Further, we could not map certain reports precisely when the description provided by an entity did not clearly state the exact location of the observation or conflict. In these cases, we mapped the report as closely as possible based on the description provided. Other biases include temporal and spatial biases. Temporal bias occurred because sightings of coyotes are more likely to take place during the day, when people are more active, than during the night. Reports may therefore overemphasize locations coyotes frequent during the day and underemphasize sites where they are active at night. Spatial bias occurred because individuals report sightings more often in areas where people frequent, such as residential neighborhoods or parks, and where visibility is not limited (Quinn 1995). Spatial bias may also occur if urban residents, who may not usually see coyotes, are more likely to file reports than residents of rural areas. Because of these biases, we focused our spatial analyses on coyote conflicts only, which because of their more serious nature, were less likely to be affected by reporting biases; a recent evaluation of coyote reports in Calgary, Canada, employed a similar strategy (Lukasik and Alexander 2011). Further, our primary focus in this study was the occurrence of direct conflicts between humans, pets, and coyotes in the DMA, rather than observations of coyote presence that did not represent a severe management concern. However, we still considered the coyote observation data to be useful for other purposes, including temporal 
analyses and describing patterns of coyote sightings and interactions in the DMA.

\section{RESULTS}

We obtained 4,006 coyote reports from the 22 entities in the DMA; $87.3 \%(3,496)$ were observations and $12.7 \%(510)$ were conflicts (Table 1). Of the observations, $2.2 \%$ (78) were signs, $86.5 \%(3,023)$ were sightings, and $11.3 \%(395)$ were encounters. Of the conflicts, $5.1 \%$ (26) were incidents, $92.4 \%$ (471) were pet-attacks, and $2.5 \%$ (13) were human-attacks. For the 13 human-attacks, 6 (46.1\%) had additional notes indicating pets were associated with the attack, 4 (30.8\%) were attacks on humans not involving pets, and the remaining $3(23.1 \%)$ did not have additional information. For the 471 pet-attacks, 247 (52.4\%) had additional information that allowed further characterization. Regarding context, 113 $(45.8 \%)$ were pet-attacks near a house, $50(20.2 \%)$ were pet-attacks in a fenced yard, $13(5.3 \%)$ were attacks of dogs off-leash, and $2(0.8 \%)$ were attacks of dogs on-leash; 69 reports $(27.9 \%)$ had no additional information on context. For type of pet, 188 (76.1\%) were attacks on dogs, 54 (21.9\%) were attacks on cats, $2(0.8 \%)$ were attacks on farm animals, and $3(1.2 \%)$ were unknown.

The date (including both month and year) was unknown for $43(1.1 \%)$ of the 4,006 coyote reports. Of the remaining 3,963 reports, most $(92.5 \%)$ were recorded from January 2007 to June 2010, and 55.0\% of observations and 57.0\% of conflicts were recorded in 2009 (Fig. 2). The month could not be determined for 360 reports (9.0\%): 8 signs, 299 sightings, 12 encounters, 38 pet-attacks, and 3 humanattacks. The remaining 3,646 coyote reports were more frequent during the winter months for both observations and conflicts (Dec-Mar for observations, Dec-Feb for conflicts; Fig. 3). The frequency of coyote reports varied by season $\left(\chi_{2}^{2}=340, P<0.001\right)$, with the greatest percentage of reports (47.5\%) occurring during the breeding season (1 Jan-30 Apr).

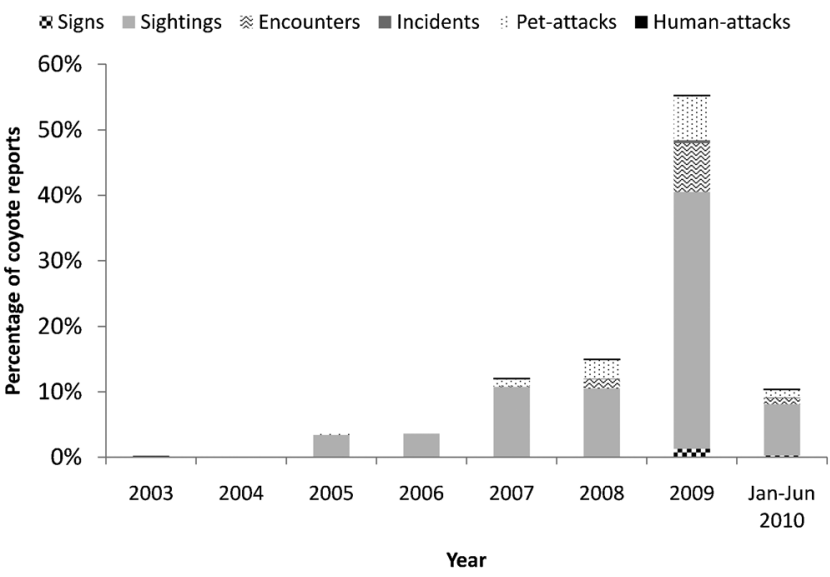

Figure 2. Temporal trends of coyote reports in the Denver Metropolitan Area for 2003-2010, presented by report type. Data are shown as the percentages of total coyote reports (summed across years) that were recorded each year $(n=3,963$ coyote reports with a known date). Data for the year 2010 were only collected from January through June.

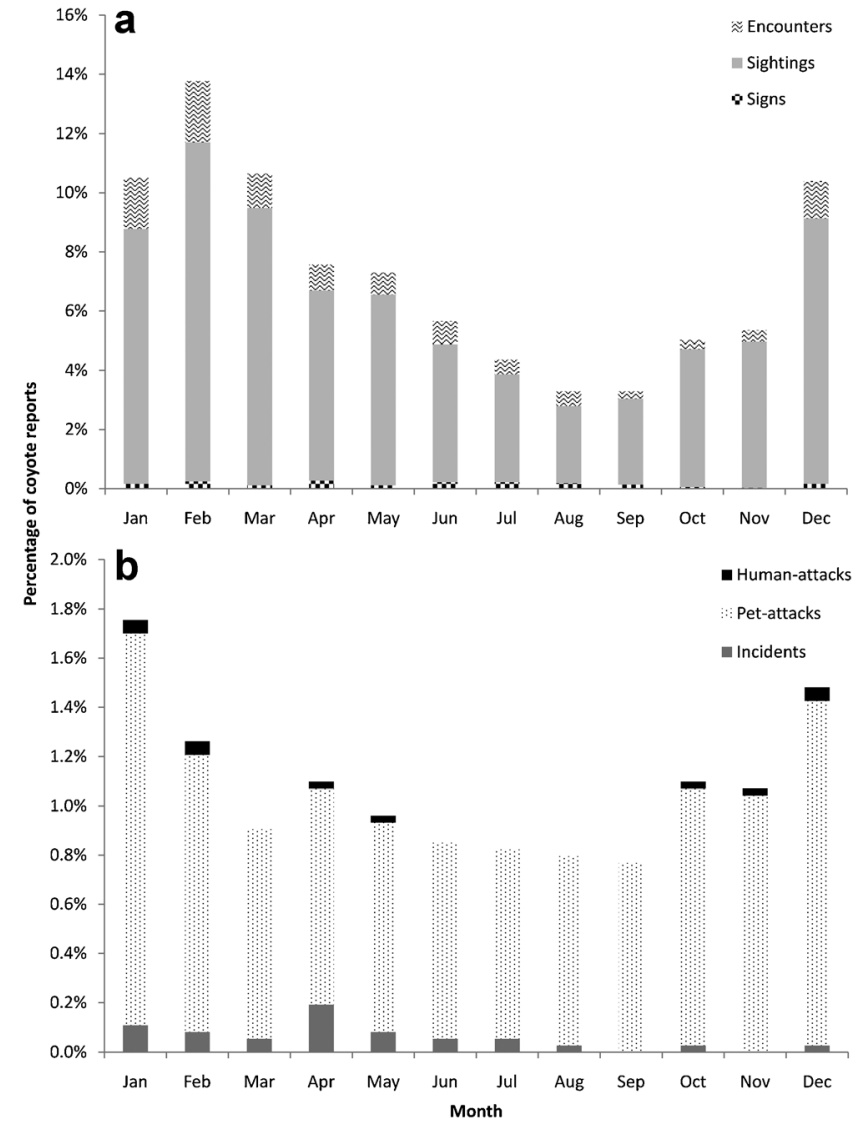

Figure 3. Monthly trends of coyote reports in the Denver Metropolitan Area for 2003-2010 for (a) observations and (b) conflicts, presented by report type. We calculated monthly percentages by dividing the number of reports (summed across years) for each month by the total number of reports (summed across all months and years; $n=3,646$ coyote reports with a known month).

Of the 499 coyote conflicts with location information, the majority was concentrated primarily in the southern portion of the DMA (Fig. 1), and conflicts were significantly clustered throughout the study area based on Ripley's $K^{-}$ function. The distribution of coyote conflicts among land cover types differed from expected based on land cover area $\left(\chi_{3}^{2}=630, P<0.001 ;\right.$ Table 3$)$. Coyote conflicts were reported more often than expected in the development and open space land cover types and less often than expected in natural and agricultural areas. The reported number of coyote conflicts in the housing density classes differed from the expected number based on housing density area $\left(\chi_{3}^{2}=661, P<0.001 ;\right.$ Table 4$)$. Coyote conflicts were reported more often than expected in the suburban class and less often than expected in the rural and exurban classes.

\section{DISCUSSION}

Our results demonstrated what we believe to be a fairly robust seasonal trend in coyote-human interactions in the DMA. Coyote observations were reported more than twice as often on average during winter than any other time of year. Similarly, coyote conflicts, including average monthly petattacks, increased more than 1.5 times during winter compared to other times of the year. Similar to our study, coyote 
Table 3. Coyote conflicts relative to land cover types in the Denver Metropolitan Area, 2003-2010.

\begin{tabular}{|c|c|c|c|c|c|c|c|}
\hline $\begin{array}{l}\text { Land } \\
\text { cover type }\end{array}$ & $\begin{array}{c}\text { Total area } \\
\left(\mathbf{k m}^{2}\right)\end{array}$ & $\begin{array}{l}\text { Proportion of } \\
\text { total area }\end{array}$ & $\begin{array}{c}\text { Expected } \\
\text { coyote reports }^{\mathrm{a}}\end{array}$ & $\begin{array}{c}\text { Observed } \\
\text { coyote reports }\end{array}$ & $\begin{array}{c}\text { Proportion } \\
\text { observed }\end{array}$ & $\begin{array}{l}95 \% \mathrm{CI} \text { for } \\
\text { proportion observed }^{\mathrm{b}}\end{array}$ & $\begin{array}{l}\text { Land cover } \\
\text { occurrence }^{c}\end{array}$ \\
\hline Natural & $3,156.0$ & 0.582 & 290 & 97 & 0.194 & $0.150-0.239$ & - \\
\hline Development & $1,151.0$ & 0.212 & 106 & 280 & 0.561 & $0.506-0.617$ & + \\
\hline Open space & 398.9 & 0.073 & 37 & 114 & 0.229 & $0.182-0.275$ & + \\
\hline Agriculture & 721.0 & 0.133 & 66 & 8 & 0.016 & $0.002-0.030$ & - \\
\hline Total & $5,426.9$ & 1.000 & 499 & 499 & 1.000 & & \\
\hline
\end{tabular}

${ }^{\text {a }}$ Calculated by multiplying proportion of total area for each habitat type by $n=499$.

${ }^{\mathrm{b}}$ Bonferroni confidence intervals (Neu et al. 1974), representing the theoretical proportion of coyote reports in each habitat type.

${ }^{\mathrm{c}}+$ Occurrence greater than expected in habitat type; -occurrence less than expected in habitat type.

attacks on dogs also peaked during winter in the Chicago metropolitan area during 1990-2007 (Gehrt and Riley 2010). In contrast to our results, however, Lukasik and Alexander (2011) found that human-coyote conflicts, and specifically pet-attacks, in Calgary were most severe from 1 May to 31 August (pup-rearing season) and least severe from 1 January to 30 April (breeding season). Lukasik and Alexander (2011) hypothesized that coyote attacks on pets peak during pup-rearing, presumably because coyotes are protecting pups from attacks by dogs. Our results do not support this idea, and alternative hypotheses to explain the seasonal patterns we observed include: 1) coyotes frequent developed areas more often in winter to search for more easily accessible food when maintenance costs increase (Bekoff and Wells 1981), 2) coyotes are more aggressive and territorial, especially toward other canids, during their breeding season, and 3) as winter days become shorter, schedules for dogwalkers and recreationists are more likely to coincide with crepuscular coyote activity patterns. Because other studies of coyote conflicts have found differing seasonal results (e.g., Lukasik and Alexander 2011) or no seasonal relationship in conflicts (e.g., White and Gehrt 2009), the extent to which the seasonal pattern we documented can be generalized to other urban systems is currently unclear.

Our results also revealed several spatial relationships. First, coyote conflicts were more frequent than expected in developed and open space land cover types and in the suburban housing density class, in contrast to natural and agriculture land cover types and exurban and rural housing densities, which had disproportionately fewer conflicts. Although coyotes tend to select natural habitats within their home ranges and minimize exposure to human development (Quinn 1997,
Grinder and Krausman 2001a, Riley et al. 2003, Atwood et al. 2004, Gehrt et al. 2009), conflicts likely were reported more often in more developed areas because of their greater concentration of humans and greater probability of interactions between pets and coyotes. This pattern emphasizes that the data reported here likely reflect not only space use of coyotes, but also the density of humans available to interact with them and report conflicts (Quinn 1995). Future research on coyote space use and movement patterns will be valuable in determining how coyotes use the landscape in and around the DMA.

An additional spatial pattern indicated that entities in the southern portion of the DMA reported more coyote conflicts than other areas. The southern region of the DMA is surrounded in 3 directions by natural land cover (Fig. 1), allowing coyotes easier access to development than other regions of the DMA where natural areas primarily occur to the west. Hence, coyotes may be using these southern areas more often than less accessible developed space in the region. However, possible reporting biases also may contribute to this pattern. For example, most of the entities in the southern region used an online reporting system to receive coyote reports from citizens, a system that was not used by all entities in the DMA and one which might increase the number of conflicts reported because of the ease and convenience of online reporting. Future human dimensions research should help determine the extent of possible reporting biases by citizens in various regions of the DMA.

Most coyote reports (87\%) in the DMA were observations, such as sightings and other evidence of coyotes, which did not involve direct conflicts between humans, pets, and coyotes. Inferring patterns, especially from the observation data,

Table 4. Coyote conflicts relative to housing density types in the Denver Metropolitan Area, 2003-2010.

\begin{tabular}{|c|c|c|c|c|c|c|c|}
\hline $\begin{array}{l}\text { Housing } \\
\text { density type }\end{array}$ & $\begin{array}{c}\text { Total area } \\
\left(\mathrm{km}^{2}\right)\end{array}$ & $\begin{array}{l}\text { Proportion of } \\
\text { total area }\end{array}$ & $\begin{array}{c}\text { Expected } \\
\text { coyote reports }^{\mathrm{a}}\end{array}$ & $\begin{array}{c}\text { Observed } \\
\text { coyote reports }\end{array}$ & $\begin{array}{c}\text { Proportion } \\
\text { observed }\end{array}$ & $\begin{array}{c}95 \% \text { CI for } \\
\text { proportion observed }^{b}\end{array}$ & $\begin{array}{c}\text { Housing density } \\
\text { occurrence }\end{array}$ \\
\hline Rural & 805.1 & 0.214 & 93 & 8 & 0.018 & $0.002-0.034$ & - \\
\hline Exurban & $1,571.3$ & 0.418 & 183 & 56 & 0.128 & $0.088-0.168$ & - \\
\hline Suburban & 693.3 & 0.185 & 81 & 280 & 0.641 & $0.583-0.698$ & + \\
\hline Urban & 686.0 & 0.183 & 80 & 93 & 0.213 & $0.164-0.262$ & 0 \\
\hline Total & $3,755.7$ & 1.000 & 437 & 437 & 1.000 & & \\
\hline
\end{tabular}

${ }^{\text {a }}$ Calculated by multiplying proportion of total area for each housing density class by $n=437$.

${ }^{\mathrm{b}}$ Bonferroni confidence intervals (Neu et al. 1974), representing the theoretical proportion of coyote reports in each housing density class.

${ }^{\mathrm{c}}+$ Occurrence greater than expected in housing density class; - occurrence less than expected in housing density class; 0 occurrence proportional to area of housing density class. 
should be done with caution because reporting bias likely differed between entities, years, types of reports, and types of citizens and thus may not reflect true patterns in interactions between humans and coyotes. For example, the annual number of observations in the DMA rose during the last 3.5 years, and reports spiked during 2009 (Fig. 2), but we are uncertain how these trends may have been influenced by changes in systems for tracking coyote interactions and changes in the probability of the public reporting them. Further, most entities (77\%) did not report any human-coyote interactions before 2007, and numerous press articles that were published in 2009 on urban coyote conflicts in the DMA might have increased reporting probability. However, the surge in media attention in 2009 also could have indicated a rise in humancoyote conflicts. In contrast to the observation data, we do suggest that the more severe the human-coyote conflict, the more likely the public was to report that conflict. Thus, we believe that the human-attack and pet-attack data in particular were less likely to be biased than the observation data and warranted more detailed investigation.

Only 13 reports ( $<3 \%$ of conflicts) during the 8-year period were attacks on humans. These results suggest that coyotes posed a relatively minor risk to human health and safety within the DMA and mirror results from other studies (Gehrt et al. 2009, Lukasik and Alexander 2011). To emphasize this point, we compared the numbers of coyote conflicts in the DMA relative to other types of animalrelated conflicts. For example, the City of Aurora reported 209 dog attacks on humans during 2009, whereas only 2 coyote conflicts ( 1 incident and 1 attack) occurred during this same time period. Likewise, Jefferson County reported 327 dog attacks on humans during 2009, but only 1 coyote conflict ( 1 incident). Of the 13 reports of coyote attacks on humans, 10 had additional information that allowed us to further characterize the report, and 6 of these indicated pets were involved in the attack. Coyote attacks on humans in the DMA are likely incidental and caused primarily by coyotes first attacking a pet, then a human intervening and subsequently being bitten. We caution, however, that interactions between humans and coyotes are dynamic, potentially shifting over time, and that coyotes can pose a threat to people, particularly if animals are fed by humans (White and Gehrt 2009, Gehrt and Riley 2010).

Coyotes in the DMA posed a more notable threat to pets; 471 (92\%) reported conflicts were pet-attacks and nearly all of these occurred within the 3.5-year period January 2007June 2010. Attack rates of coyotes on pets have been shown to vary within and across urban systems (Crooks and Soulé 1999, Gehrt et al. 2009, Grubbs and Krausman 2009), suggesting differences in coyote behavior or human behavior, including how pets are allowed to interact with coyotes, management and education strategies, or reporting mechanisms. Of the 178 pet-attack reports with additional information regarding context of the attack, most of them (92\%) involved coyotes either entering a backyard or coming close to a house and attacking a pet. Surprisingly, fewer conflicts (15) involved dogs in open space areas, and most of these (87\%) involved dogs off-leash, although this low number could in part reflect bias in reporting rates (e.g., dog-owners who allow their dogs off-leash in leash-only areas may be less likely to report a conflict). If this trend is indeed indicative of coyote conflicts in the DMA, then managers should emphasize strategies that preclude coyotes from entering yards and attacking pets, including the removal of attractants in yards, and underscore supervision of pets by owners when outdoors and keeping pets on-leash in open space areas.

Although the more severe types of coyote conflicts, such as attacks on pets or humans, are relatively rare in the DMA, these conflict situations can have significant consequences on a local scale. For many people, a situation involving a coyote attacking or killing a pet or an interaction with an aggressive animal is a traumatic experience that can reduce tolerance for wildlife. Minimizing these extreme forms of conflicts should be a high priority for management authorities and can be approached by implementing efforts to either manage coyotes or change human behavior. The entities within the DMA currently vary in the techniques they use to address human-coyote conflicts, including lethal control as well as education and non-lethal efforts. Research is currently underway in the DMA to develop effective non-lethal methods for preventing human-coyote conflicts and to provide more tools for urban wildlife managers. Because conflict occurrences are often rooted in or exacerbated by social factors, for example people feeding coyotes, public education is an important consideration in this context, as it may help achieve human behavior changes. Our results indicate that timing press releases as well as safety and awareness information to anticipate seasonal increases in coyote activity and conflict while focusing educational messages on pet safety, especially in open space or developed areas, might be effective strategies. Additional strategies to emphasize in educational campaigns aimed at raising awareness and promoting human behavior changes include understanding the appropriate response if approached by a coyote, avoiding the feeding of wildlife, ensuring that pet food is inaccessible to coyotes, securing trash, supervising pets at all times when outdoors (even in yards), leashing pets in natural areas and parks where coyotes may frequent, and implementing landscaping and fencing designed to exclude coyotes and other wildlife from yards (U.S. Department of Agriculture 2002, Curtis and Hadidian 2010). Although coyotes may continue to be observed, continuously enforcing these steps should minimize the frequency of coyote conflicts in urban areas. To inform these management and educational initiatives, human dimensions research aimed at understanding human attitudes and behaviors and exploring the social dimensions of human-coyote conflicts is essential.

\section{MANAGEMENT IMPLICATIONS}

We suggest that municipalities develop a written coyote management plan that outlines programs and strategies that can be implemented to resolve human-coyote conflicts (e.g., City of Centennial 2009). We also recommend that the different entities within the DMA strive to achieve more accurate and consistent reporting mechanisms for public observations of and conflicts with coyotes, including 
documentation of correct addresses and detailed descriptions that clearly state the location and define the nature of each coyote report. A standardized coyote reporting form has recently been developed by a regional team of urban coyote researchers and managers. Use of this type of reporting form would greatly improve abilities to compare across systems and to detect trends. A comprehensive coyote reporting database with accurate locations and common language that describes interactions is necessary to correctly categorize and map locations of coyote reports, more effectively identify conflict hotspots, and apply targeted solutions to conflicts based on geographic, as well as social and biological, dimensions. Such a database will be invaluable to both wildlife management agencies and the public in continuing to minimize human-coyote conflicts throughout the DMA. These efforts should also contribute to a national endeavor that will help other urban centers in reporting and managing their coyote conflicts.

\section{ACKNOWLEDGMENTS}

The following entities provided funding to support this research: Adams County, City of Lakewood, City of Aurora, City and County of Denver, Jefferson County, Colorado State University, and USDA-WS-National Wildlife Research Center. We thank the employees of Colorado Parks and Wildlife, USDA-Wildlife ServicesColorado, and each of the additional 21 entities in the DMA that provided their data on coyote observations and conflicts. We thank the City of Aurora for providing their initial map of coyote reports containing the categories we eventually used for this study. We appreciate the assistance of C. Burdett in obtaining spatial datasets. We also thank J. Daigle and 2 anonymous referees for providing comments that improved the manuscript.

\section{LITERATURE CITED}

Atwood, T. C., H. P. Weeks, and T. M. Gehring. 2004. Spatial ecology of coyotes along a suburban-to-rural gradient. Journal of Wildlife Management 68:1000-1009.

Baruch-Mordo, S., S. W. Breck, K. R. Wilson, and D. M. Theobald. 2008. Spatiotemporal distribution of black bear-human conflicts in Colorado, USA. Journal of Wildlife Management 72:1853-1862.

Beier, P. 1995. Dispersal of juvenile cougars in fragmented habitat. Journal of Wildlife Management 59:228-237.

Bekoff, M., and E. M. Gese. 2003. Coyote (Canis latrans). Pages 467-481 in G. A. Feldhamer, B. C. Thompson, and J. A. Chapman, editors. Wild mammals of North America: biology, management, and conservation. Second edition. The Johns Hopkins University Press, Baltimore, Maryland, USA.

Bekoff, M., and M. C. Wells. 1981. Behavioural budgeting by wild coyotes: the influence of food resources and social organization. Animal Behaviour 29:794-801.

Bruce, B. W., and P. B. McMahon. 1996. Shallow ground-water quality beneath a major urban center: Denver, Colorado, USA. Journal of Hydrology 186:129-151.

Byers, C. R., and R. K. Steinhorst. 1984. Clarification of a technique for analysis of utilization-availability data. Journal of Wildlife Management 48:1050-1053.

City of Centennial. 2009. City of Centennial, Colorado, coyote management plan. http://www.centennialcolorado.com/DocumentView.aspx? $\mathrm{DID}=2341$. Accessed 6 October 2011.

Crooks, K. R. 2002. Relative sensitivities of mammalian carnivores to habitat fragmentation. Conservation Biology 16:488-502.
Crooks, K. R., and M. E. Soulé. 1999. Mesopredator release and avifaunal extinctions in a fragmented system. Nature 400:563-566.

Curtis, P. D., and J. Hadidian. 2010. Responding to human-carnivore conflicts in urban areas. Pages 201-211 in S. D. Gehrt, S. P. D. Riley, and B. L. Cypher, editors. Urban carnivores: ecology, conflict, and conservation. The Johns Hopkins University Press, Baltimore, Maryland, USA.

Denver Post. 2010. Denver Post website. http://www.denverpost.com/. Accessed 15 June 2010.

Denver Regional Council of Governments. 2010. 2007 population and household estimates. http://www.drcog.org/documents/Final\%200607 PopTableByCounty.pdf. Accessed 6 October 2011.

Fuller, T. K., S. DeStefano, and P. S. Warren. 2010. Carnivore behavior and ecology, and relationship to urbanization. Pages 13-19 in S. D. Gehrt, S. P. D. Riley, and B. L. Cypher, editors. Urban carnivores: ecology, conflict, and conservation. The Johns Hopkins University Press, Baltimore, Maryland, USA.

Gehring, T. M., and R. K. Swihart. 2003. Body size, niche breadth, and ecologically scaled responses to habitat fragmentation: mammalian predators in an agricultural landscape. Biological Conservation 109:283-295.

Gehrt, S. D. 2010. The urban ecosystem. Pages 3-11 in S. D. Gehrt, S. P. D. Riley, and B. L. Cypher, editors. Urban carnivores: ecology, conflict, and conservation. The Johns Hopkins University Press, Baltimore, Maryland, USA.

Gehrt, S. D., C. Anchor, and L. A. White. 2009. Home range and landscape use of coyotes in a metropolitan landscape: conflict or coexistence? Journal of Mammalogy 90:1045-1057.

Gehrt, S. D., and S. P. D. Riley. 2010. Coyotes (Canis latrans). Pages 79-95 in S. D. Gehrt, S. P. D. Riley, and B. L. Cypher, editors. Urban carnivores: ecology, conflict, and conservation. The Johns Hopkins University Press, Baltimore, Maryland, USA.

Gehrt, S. D., S. P. D. Riley, and B. L. Cypher, editors. 2010. Urban carnivores: ecology, conflict, and conservation. The Johns Hopkins University Press, Baltimore, Maryland, USA.

Grinder, M., and P. R. Krausman. 1998. Coyotes in urban areas: conflicts and solutions. Pages 235-243 in U.S./Mexico 65 Cross border waters: fragile treasures for the 21st century: ninth U.S./Mexico Border States conference on recreation, parks and wildlife. U.S. Forest Service Rocky Mountain Research Station, 3-6 June 1998, Tucson, Arizona, USA.

Grinder, M. I., and P. R. Krausman. 2001a. Home range, habitat use, and nocturnal activity of coyotes in an urban environment. Journal of Wildlife Management 65:887-898.

Grinder, M., and P. R. Krausman. 2001b. Morbidity-mortality factors and survival of an urban coyote population in Arizona. Journal of Wildlife Diseases 37:312-317.

Grubbs, S. E., and P. R. Krausman. 2009. Observations of coyote-cat interactions. Journal of Wildlife Management 73:683-685.

Haase, P. 1995. Spatial pattern analysis in ecology based on Ripley's $K$ function: introduction and methods of edge correction. Journal of Vegetation Science 6:575-582.

Hudenko, H. W., W. F. Siemer, and D. J. Decker. 2010. Urban carnivore conservation and management: the human dimension. Pages 21-33 in S. D. Gehrt, S. P. D. Riley, and B. L. Cypher, editors. Urban carnivores: ecology, conflict, and conservation. The Johns Hopkins University Press, Baltimore, Maryland, USA.

Knowlton, F. F., E. M. Gese, and M. M. Jaeger. 1999. Coyote depredation control: an interface between biology and management. Journal of Range Management 52:398-412.

Levy, S. 2012. The new top dog. Nature 485:296-297.

Lukasik, V. M., and S. M. Alexander. 2011. Human-coyote interactions in Calgary, Alberta. Human Dimensions of Wildlife 16:114-127.

Magle, S. B., P. Reyes, J. Zhu, and K. R. Crooks. 2010. Extirpation, colonization, and habitat dynamics of a keystone species along an urban gradient. Biological Conservation 143:2146-2155.

Mansfield, T. M., and S. G. Torres. 1994. Trends in mountain lion depredation and public safety threats in California. Pages 12-14 in Proceedings of the sixteenth vertebrate pest conference. University of California, 1-3 March 1994, Davis, California, USA.

Marzluff, J. M., E. Schulenberger, W. Endlicher, M. Alberti, G. Bradley, C. Ryan, U. Simon, and C. ZumBrunnen. 2008. Urban ecology: an international perspective on the interaction between humans and nature. Springer Science, New York, New York, USA. 
Mcdonald, R. I., P. Kareiva, and R. T. T. Forman. 2008. The implications of current and future urbanization for global protected areas and biodiversity conservation. Biological Conservation 141:1695-1703.

McKinney, M. L. 2002. Urbanization, biodiversity, and conservation. BioScience 52:883-890.

Morey, P. S., E. M. Gese, and S. Gehrt. 2007. Spatial and temporal variation in the diet of coyotes in the Chicago metropolitan area. American Midland Naturalist 158:147-161.

Neu, C. W., C. R. Byers, and J. M. Peek. 1974. A technique for analysis of utilization-availability data. Journal of Wildlife Management 38:541545.

Pickett, S. T. A., M. L. Cadenasso, J. M. Grove, P. M. Groffman, L. E. Band, C. G. Boone, W. R. Burch, Jr., C. S. B. Grimmond, J. Hom, J. C. Jenkins, N. L. Law, C. H. Nilon, R. V. Pouyat, K. Szlavecz, P. S. Warren, and M. A. Wilson. 2008. Beyond urban legends: an emerging framework of urban ecology, as illustrated by the Baltimore Ecosystem Study. BioScience 58:139-150.

Quinn, T. 1995. Using public sighting information to investigate coyote use of urban habitat. Journal of Wildlife Management 59:238245.

Quinn, T. 1997. Coyote (Canis latrans) food habits in three urban habitat types of western Washington. Northwest Science 71:1-5.

Riley, S. P. D., J. Hadidian, and D. A. Manski. 1998. Population density, survival, and rabies in raccoons in an urban national park. Canadian Journal of Zoology 76:1153-1164.

Riley, S. P. D., R. M. Sauvajot, T. K. Fuller, E. C. York, D. A. Kamradt, C. Bromley, and R. K. Wayne. 2003. Effects of urbanization and habitat fragmentation on bobcats and coyotes in southern California. Conservation Biology 17:566-576.

Rollins, M. G., and C. K. Frame. 2006. The LANDFIRE prototype project: nationally consistent and locally relevant geospatial data for wildland fire management. U.S. Forest Service General Technical Report RMRSGTR-175, Rocky Mountain Research Station, Fort Collins, Colorado, USA.

SAS Institute Inc. 2008. SAS/STAT ${ }^{\circledR} 9.2$ user's guide. SAS Institute Inc., Cary, North Carolina, USA.

Theobald, D. M. 2005. Landscape patterns of exurban growth in the USA from 1980 to 2020. Ecology and Society 10:32.

Thirgood, S., R. Woodroffe, and A. Rabinowitz. 2005. The impact of human-wildlife conflict on human lives and livelihoods. Pages 13-26 in R. Woodroffe, S. Thirgood, and A. Rabinowitz, editors. People and wildlife: conflict or coexistence? Cambridge University Press, Cambridge, United Kingdom.

Tigas, L. A., D. H. Van Vuren, and R. M. Sauvajot. 2002. Behavioral responses of bobcats and coyotes to habitat fragmentation and corridors in an urban environment. Biological Conservation 108:299-306.

U.S. Department of Agriculture, Animal and Plant Health Inspection Service, Wildlife Services. 2002. Urban and suburban coyotes. Factsheet, April 2002.

White, L. A., and S. D. Gehrt. 2009. Coyote attacks on humans in the United States and Canada. Human Dimensions of Wildlife 14:419-432.

Associate Editor: John Daigle. 